\title{
Exchange Rates, Inflation and Monetary Policy Objectives in Open Economies: The Experience of Chile
}

\author{
Rodrigo Caputo* \\ Faculty of Economics and Politics \\ Cambridge University. \\ rec39@econ.cam.ac.uk
}

A pril 16, 2004

\begin{abstract}
A bstract
This paper characterizes, empirically, the conduct of monetary policy in a small open economy. In particular, using as a case study the Chilean inflation targeting experience, we assess the role of the exchange rate in the determination of the interest rate. We conclude that Chile has adopted what Svensson (1997) calls a gradual approach to targeting inflation. This means, in practice, that the central bank modifies its policy instrument, the interest rate, whenever expected inflation or output deviate from its target. In this context, we find evidence that the monetary authorities also react to real exchange rate misalignments. This reaction is comparatively larger than that found in developed economies. Finally, the evidence, although not conclusive, seems to suggest a non linear response to exchange rate misalignments: the central bank reacts strongly to large deviations rather than to small ones.
\end{abstract}

${ }^{*}$ This article is part of my PhD dissertation at Cambridge University. I am grateful to my supervisors Dr. Petra Geraats and Dr. Peter Tinsley for their constant support and orientation. 


\section{Introduction}

Inflation targeting has become the new paradigm in monetary policy. As is noted by Fry et al (2000), between 1990 and 1998 the number of countries with explicit inflation targets increased from 5\% to $54 \%$. Overall, this monetary policy framework has been adopted by 54 economies throughout the world. These economies include 25 developing countries, like Chile, China, Jamaica, Tanzania and Vietnam; 16 transitional economies like the Czech Republic, Poland, Romania and Russia and 13 developed economies like Australia, Canada, New Zealand, U.K. and Sweden.

In this context, most of the countries that are pursuing inflation targeting are small open economies that use a short term interest rate $^{1}$, usually set by the central bank, as the main policy instrument. In general, however, empirical research on the way that central banks target inflation has been limited only to developed economies. In fact, Clarida et al (1998) provide structural estimations of the monetary policy reaction functions in some European countries, Japan and the USA. They conclude that an inflation forecast based (IFB) policy rule provides a good characterization of the way in which monetary policy has been conducted in those countries. In addition, they find that exchange rate considerations do not play an important role in the monetary policy design, even though most of the countries that they analyze are small open economies.

For developing countries, Calvo and Reinhart (2002) provide evidence suggesting that central banks react to exchange rate misalignments. In particular, they conclude that, in emerging economies interest rates are used as the preferred means of smoothing exchange rates fluctuations. This evidence, however, is not based on structural estimations of monetary policy rules, as in Clarida et al (1998). In fact, Calvo and Reinhart (2002), derive monetary policy rules from vector autoregressive (VAR) estimations. In these circumstances, those rules do not describe the systematic behavior of the central bank. In fact, as is noted by Clarida (2001), in a VAR equation the monetary policy response to the exchange rate does not have a clear interpretation: it can be an explicit response to exchange rate misalignments, a response to expected inflation (that is affected by the current level of the exchange rate) or, it can be a combination of the two. Therefore, a monetary policy equation, derived from a VAR, cannot be used to describe the systematic behavior of central banks.

\footnotetext{
${ }^{1}$ Central banks, in general, have abandoned the use of monetary aggregates as a policy instrument. There are two reason for this: i) interest rates are usually easier to interpret by the public and ii) given that money demand is unstable, it is difficult to predict the impact that changes in monetary aggregates will have on output and inflation.
} 
In this context, not knowing how the central bank systematically reacts to different macroeconomic disturbances may become problematic. In particular, it makes it difficult to analyze the welfare implications of alternative policy rules as well as to provide policy recommendations as to how to react in the face of various shocks.

In this chapter, we characterize the systematic behavior of the central bank in a small open and emerging economy. In particular, we investigate how the monetary authorities react to exchange rate misalignments and output deviations from trend. We follow Clarida et al (1998) and estimate an IFB rule that allows for a response to output and to the exchange rate. In this framework, these responses have a clear interpretation: they reflect the importance that output and the exchange rate have per se for the central bank. Hence, it is possible to determine whether the monetary authorities have additional objectives besides controlling inflation.

We use, as a study case, the Chilean inflation targeting experience of the nineties. This is an interesting case because Chile is a small, open and emerging economy and, as is noted by SchmidtHebbel and Tapia (2002), it was the second country in the world to adopt inflation targeting, setting its first annual target in September 1990.

The main conclusions of this chapter are as follows. First, an IFB monetary policy reaction function provides a good characterization of the way in which the Chilean central bank (CCB) designs its policy. In particular, the CCB reacts to expected inflation deviations from target. In this context, the monetary authorities follow a "flexible" approach in targeting inflation; they smooth output deviations even when inflation is on target. This means that output stability is per se a monetary policy objective. Second, exchange rate considerations play an important role in the conduct of monetary policy. In fact, besides reacting to expected inflation and output, the $\mathrm{CCB}$ moves interest rates whenever the real exchange rate deviates from trend and, compared with other inflation targeting countries, the policy response to exchange rate is larger. Third, the response to exchange rate misalignments is nonlinear; the CCB reacts more aggressively to large real exchange rate misalignments than it does to small ones. Finally, as is observed in many other countries, the CCB smooths interest rates considerably; the degree of interest rate inertia is high.

This chapter is organized as follows. Following Clarida (2001), Section 2.2 presents a simple framework in order to estimate the systematic monetary policy responses to inflation, output and the exchange 
rate. Section 2.3 discusses the main characteristics of the inflation targeting regime in place in Chile since 1990. Section 2.4 specifies the IFB monetary policy rule to be estimated and describes the way in which the relevant variables are constructed. In particular, following Harvey and Jaeger (1993), we use structural times series models to detrend the relevant variables. Section 2.5 presents the main results, whereas Section 2.6 performs some robustness exercises. Finally, Section 2.7 concludes the chapter.

\section{Identifying the Systematic Components of M onetary Policy}

As is noted by Clarida (2001), within a VAR framework it is not easy to identify the systematic responses of the monetary policy instrument to the main macroeconomic variables. In fact, the policy responses that are obtained in a VAR, either in its reduced or its structural form, do not necessarily have a structural interpretation. In this section, we illustrate this point with a simple example. In particular, following Clarida (2001), we analyze how the policy coefficients in a reduced form $\operatorname{VAR}^{2}$ may be interpreted. The aim of this example is to show why it is difficult, in a VAR framework, to determine whether a central bank in an open economy targets inflation with an independent concern for the exchange rate.

Let's assume that the central bank targets inflation in a flexible way. This means that, besides inflation, the stability in output is also an objective of monetary policy. In this case, the central bank does not target the exchange rate. In particular, suppose that the central bank's policy instrument, the interest rate, can be described by a simple IFB policy reaction function

$$
r_{t}=\rho_{\pi} E_{t}\left\{\pi_{t+n}\right\}+\rho_{y} y_{t-1}+\epsilon_{r, t}
$$

where $r_{t}$ is the interest rate controlled by the central bank, $E_{t}\left\{\pi_{t+n}\right\}$ is the expected inflation deviation from a predetermined target, $y_{t-1}$ is the lagged deviation of output from the trend level and $\epsilon_{r, t}$ is a random shock to the interest rate. The $\rho_{\pi}$ coefficient describes the systematic response to inflation shocks. On the other hand, the $\rho_{y}$ coefficient represents the systematic response to output deviations. In this case, the central bank does not have any systematic response to exchange rate misalignments.

\footnotetext{
${ }^{2}$ A more complete explanaition, that includes a structural VAR, is given in Clarida (2001).
} 
Now, assume that expected inflation depends on past information about some macroeconomic variables. In particular, expected inflation can be expressed as follows

$$
E_{t}\left\{\pi_{t+n}\right\}=\theta_{1} y_{t-1}+\theta_{2} \pi_{t-1}+\theta_{3} r_{t-1}+\theta_{4} q_{t-1}
$$

where $q_{t-1}$ is the real exchange rate $^{3}$, expressed as a percentage deviation from the steady state. On the other hand, the coefficients $\theta_{1}, \theta_{2}, \theta_{3}$ and $\theta_{4}$ represent the response of expected inflation to the lagged values of output, inflation, the interest rate and the real exchange rate, respectively. In particular, an increase in the real exchange rate has a positive impact on expected inflation, therefore $\theta_{4}>0$.

Replacing equation (2) into the monetary policy reaction function, equation (1), gives the policy interest rate equation

$$
r_{t}=\rho_{\pi}\left\{\theta_{1} y_{t-1}+\theta_{2} \pi_{t-1}+\theta_{3} r_{t-1}+\theta_{4} q_{t-1}\right\}+\rho_{y} y_{t-1}+\epsilon_{r, t}
$$

the above expression is the interest rate equation implicit in a reduced form VAR that contains the set of variables $z_{t}=\left(y_{t}, \pi_{t}, r_{t}, q_{t}\right)$. In this case, the innovation in the VAR equation (3) has a structural interpretation; however, the reduced form coefficients do not necessarily reflect the systematic responses of the central bank to the various macroeconomic variables. In particular, in this VAR, the interest rate response to real exchange rate misalignments is different from zero, but it does not have a structural interpretation. This response is given by

$$
\frac{\partial r_{t}}{\partial e_{t-1}}=\rho_{\pi} \theta_{4}>0
$$

and reflects the fact that the exchange rate influences the interest rate only because it is an indicator of future inflation and not because the exchange rate is a policy objective per se. The response in (4) is the product of the policy reaction to expected inflation, $\rho_{\pi}$, and the response of the inflation forecast to an exchange rate depreciation, $\theta_{4}$. Hence, the VAR evidence suggests a positive policy response to the exchange rate even if this variable is not an explicit policy objective.

\footnotetext{
${ }^{3}$ The real exchange rate is defined as $q_{t}=p_{t}^{*}+e_{t}-p_{t}$ where $p_{t}^{*}$ is the level of foreign prices (in logs), $e_{t}$ is the nominal exchange rate (in logs) reflecting the domestic price of foreign currency and $p_{t}$ is the domestic consumer price index (in $\operatorname{logs})$. Hence, an increase in $q_{t}$ is a depreciation.
} 
Now, consider the alternative case in which the real exchange rate is per se a policy objective. In such a case, the IFB rule in (1) takes the form

$$
r_{t}=\rho_{\pi} E_{t}\left\{\pi_{t+n}\right\}+\rho_{y} y_{t-1}+\rho_{q} q_{t-1}+\epsilon_{r, t}
$$

where the $\rho_{q}$ coefficient captures the systematic policy response to exchange rate misalignments. As before, expected inflation evolves according to equation (2). Now, replacing equation (2) into equation (5) gives the policy interest rate equation

$$
r_{t}=\rho_{\pi}\left\{\theta_{1} y_{t-1}+\theta_{2} \pi_{t-1}+\theta_{3} r_{t-1}+\theta_{4} q_{t-1}\right\}+\rho_{y} y_{t-1}+\rho_{q} q_{t-1}+\epsilon_{r, t}
$$

which, again, represents the interest rate equation derived from a VAR. In this case, the interest rate response to the real exchange rate is given by

$$
\frac{\partial r_{t}}{\partial e_{t-1}}=\rho_{\pi} \theta_{4}+\rho_{q}>0
$$

where the above response contains two elements, the systematic policy reaction to the exchange rate, $\rho_{q}$, and the policy response to the exchange rate component of the expected inflation, $\rho_{\pi} \theta_{4}$. Hence, when the exchange rate is a policy objective per se, the VAR response will be positive. However, this response will incorporate both the systematic reaction to the exchange rate and the reaction to expected inflation. In short, from the VAR the $\rho_{q}$ coefficient cannot be obtained. Also, another drawback of the VAR approach is that, in general, the other monetary policy coefficients, $\rho_{\pi}$ and $\rho_{y}$ cannot be recovered either.

The above exercise has shown that, in a VAR framework, it is difficult to interpret the interest rate response to the exchange rate. More specifically, from the VAR coefficients the systematic policy response to the real exchange rate cannot be identified.

To overcome this identification problem, Clarida et al (1998) and Clarida (2001) suggest that one should estimate, directly, the IFB monetary policy rule in equation (5) using the Generalized Method of Moments (GMM). This approach has the advantage of providing an estimate of $\rho_{q}$ and enables the researcher to test, using a simple t-ratio test, whether the exchange rate is, per se, a policy objective of the central bank. In particular, if $H_{0}: \rho_{q}=0$ is rejected, then the exchange rate is not a policy target. 
In this chapter, we follow Clarida et al (1998) and identify the systematic components of the Chilean monetary policy by estimating, directly, a policy specification like equation (5).

\section{Specifying an IFB M onetary Policy Rule for Chile}

In this section we briefly describe the institutional framework in which the CCB operates. In this context, we specify an IFB monetary policy reaction function relevant for Chile.

\subsection{M onetary and Exchange R ate Policies in Chile}

The 1980 Chilean Constitution empowers the CCB to "stabilize the value of the currency and provide normality in the functioning of internal and external payments". This statement has been interpreted as giving three main objectives to the CCB: to control inflation, to provide a sound regulation of the banking system and to avoid situations that may lead to currency crises.

From 1980 to 1990, the CCB did not have any explicit target for inflation. It is only from 1990 that the $\mathrm{CCB}$ adopted an explicit inflation targeting regime. The procedure works as follows: each September, in its Report to the Congress, the CCB announces the CPI inflation target for the end of the following year (December year-on-year CPI inflation). This means that the target is announced fifteen months in advance. In practice, the target was gradually adjusted so as to allow for a gradual reduction of inflation. In fact, in 1990, the target for the following year was set at 27\%, whereas in 2001 the target was $3 \%$ (see Figure $1^{4}$ ).

As is noted by Parrado (2001), the inflation targeting regime allows for flexibility; there is no legal mandate to achieve the target each year. This flexibility, along with the gradual adjustment of the inflation target, have contributed to maintaining high rates of real GDP growth: on average a $6.7 \%$ annual growth rate between 1990 and 2000.

Since 1985, the interest rate has been the main instrument of monetary policy. From 1985 to April 1995, the CCB used a short-term (three months) interest rate indexed to the CPI inflation. In May 1995, the CCB changed its policy instrument to an overnight indexed interest rate which is controlled through

\footnotetext{
${ }^{4}$ As in Gallego et al (2002), the inflation target series is a linear interpolation of the Chilean central bank Decemberto-December targets.
} 
Figure 1: Chile: Inflation Target (in \%).

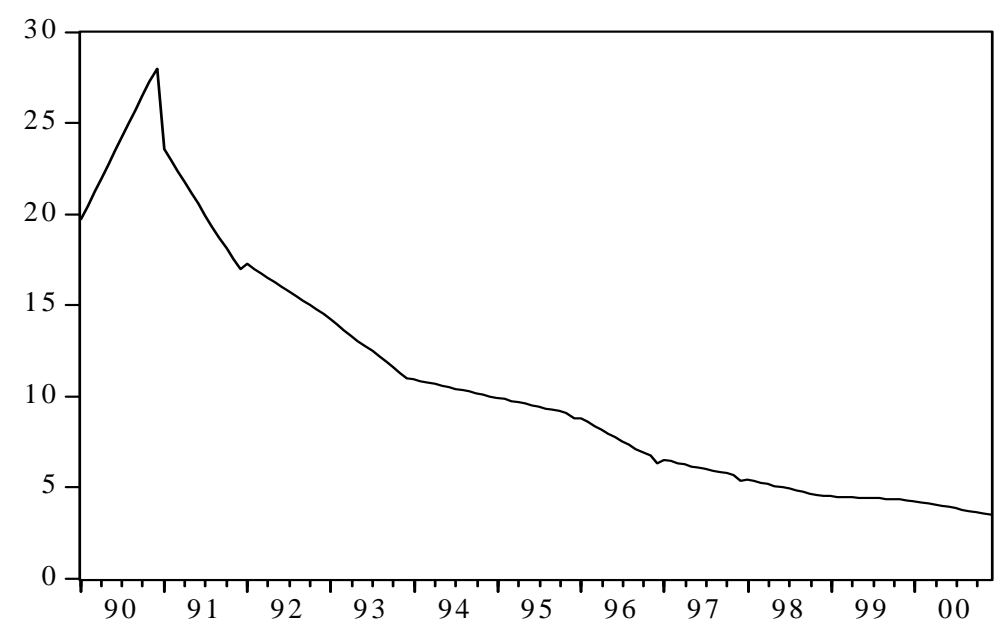

open-market operations. Those operations are performed by issuing CCB papers and by conducting repos and anti-repos.

As pointed out by Valdes (1997), the use of indexed interest rates is equivalent to setting ex - post real interest rates. In this context, there were at least three reasons for using a real interest rate as a monetary policy instrument. First, the demand for money had been unstable over the period, therefore the use of interest rate had more predictable effects over output and inflation than monetary aggregates. Second, the high degree of indexation of the Chilean economy (including financial contracts) made it difficult to use nominal interest rates. Finally, in an environment of high and unpredictable inflation, movements in the real interest rates were easy to understand and did not have double interpretations as in the case of nominal rates $^{5}$.

The CCB also has the power to set the exchange rate policy. From August 1984 to September 1999, the CCB adopted a crawling exchange rate band. As is noted by Landerretche et al (2000 p.461), the main objectives of the band were to maintain international competitiveness and reduce excessive exchange rate volatility. However, since the start of the band, many of its features, including its width, rate of crawl, reference currency basket, degree of symmetry and central parity were modified (see Figure 2). Since September 2, 1999, the country has embraced a fully-flexible exchange rate regime,

\footnotetext{
${ }^{5}$ Given a more stable, and low, path for inflation, the CCB abandoned, in August 2001, the use of real interest rates as a policy instrument. Since then, the policy instrument is an overnight nominal interest rate.
} 
Figure 2: Chile: Exchange Rate Band and Observed Exchange Rate

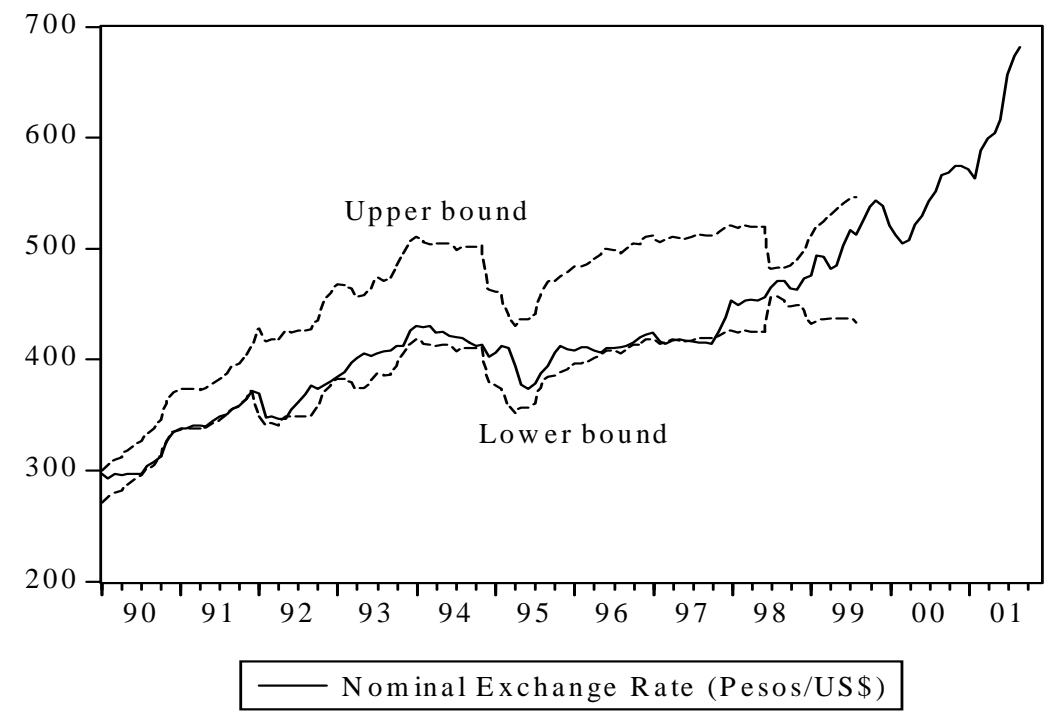

with the possibility of the monetary authority intervening in the market only if the exchange rate does not reflect the "real" value of the foreign currency (Parrado 2001, p.7).

The basic instruments that the CCB used to stabilize the nominal exchange rate, within the band, were interventions in the foreign exchange market and, in some cases, modifications to the limits of the band. As is noted by Parrado (2001), at the end of 1991, Chile's strong external accounts forced the CCB to lower the referential dollar exchange rate (central parity) by 5 percent and to widen the band to \pm 10 percent. Although this decision was taken to increase the market role in determining the exchange rate, in March 1992 it was decided that the CCB should have a "dirty" floating option to intervene within the band. In this context, intra-marginal foreign-exchange rate interventions by the CCB were frequent and, at times, intense (Landerretche et al, 2000).

The elimination of the band in September 1999, did not imply the absence of foreign exchange interventions. In fact, "in response to large exchange rate depreciation and volatility, the CCB announced and carried out a temporary policy of sterilized interventions between July 2001 and January $2002^{6}$. The stated objectives of the interventions were to reduce excessive exchange rate volatility and provide a

\footnotetext{
${ }^{6}$ The bank intervened by selling U.S. $\$ 800$ millions (less than its preannounced ceiling of U.S.\$1.5 billion) and issuing the equivalent of U.S.\$3 billion (as announced) in dollar-denominated peso CCB debt (to provide a hedge against future exchange rate devaluation), Schmidt-Hebbel and Werner (2002. p.72)
} 
hedge against future devaluations, without affecting exchange rate trends." Schmidt-Hebbel and Werner (2002. p.72).

In summary, the CCB has specific instrument for each target. In particular, the interest rate is used as the inflation targeting instrument whereas sterilized interventions in the exchange rate market, and sometimes modifications to the limits of the exchange rate band, were used as instruments of the exchange rate policy. In this context, one advantage of the framework used in this paper is that it is possible to test whether the policy interest rate was influenced by exchange rate considerations.

\subsection{A Forward-Looking Model of Policy Interest Rate}

Following Clarida et al (1998 and 2000) and Clarida (2001), we specify a forward-looking model for the monetary policy interest rate. We introduce, however, some modifications in order to obtain the ex-post real interest rate that is, in practice, the instrument that has been used by the CCB since 1985 .

In a forward-looking environment, the nominal policy interest rate will be determined by current expectations of the central bank's objectives. If we assume that the central bank is concerned about deviations of future inflation, output and the exchange rate, we can express the reaction function as follows

$$
i_{t}^{*}=\bar{i}+\rho_{\pi}\left(E_{t}\left[\pi_{t+n}\right]-\pi_{t+n}^{*}\right)+\rho_{y} y_{t}+\rho_{q} q_{t}
$$

where $i_{t}^{*}$ is the nominal interest rate set by the central bank and $\left(E_{t}\left[\pi_{t+n}\right]-\pi_{t+n}^{*}\right)$ is the deviation of expected inflation $\mathrm{n}$ periods ahead, $E_{t}\left[\pi_{t+n}\right]$, from a predetermined target $\pi_{t+n}^{*}{ }^{7}$ and $\bar{i}$ is the equilibrium nominal interest rate $^{8}$. The central bank may also be concerned about deviations of output from the equilibrium level ${ }^{9}, y_{t}$, and deviations of the real exchange rate from the steady state, $q_{t}$. It is important to notice that the parameters $\rho_{y}$ and $\rho_{q}$ capture the non-inflationary components of output and exchange rate deviations. That is, both elements may be objectives of monetary policy even when expected

\footnotetext{
${ }^{7}$ In general, the inflation target is assumed to be a fixed number. We adopt a more general approach that enables us to consider the case in which the target is changing over time. This case is of particular importance in economies were inflation is a non-stationary process, and where targets are converging gradually to the long run inflation level.

${ }^{8}$ In fact, when expected inflation, output and the real exchange rate are at their equilibrium, or target level, $\left(E_{t}\left[\pi_{t+n}\right]-\pi_{t+n}^{*}\right)=0, y_{t}=0$ and $q_{t}=0$. It follows that the interest rate is, in equilibrium, $i_{t}^{*}=\bar{i}$.

${ }^{9} \mathrm{~A}$ central bank that targets inflation with a concern for output fluctuations is following what Svensson (1997) calls a gradual approach to inflation targeting.
} 
inflation is on target; $\left(E_{t}\left[\pi_{t+n}\right]-\pi_{t+n}^{*}\right)=0$. Therefore, the specification in (8) allows us to test whether output and the exchange rate are per se objectives of the monetary authorities. In fact, as is noted in Section 2.2, under the null hypothesis that the central bank is not concerned with output and real exchange rate deviations, the coefficients $\rho_{y}$ and $\rho_{q}$ should be equal to zero.

We can re-express the monetary policy interest rate in real terms by subtracting $E_{t}\left[\pi_{t+n}\right]$ from both sides of (8) and by adding and subtracting $\pi_{t+n}^{*}$ from the right hand side of (8). Hence, the ex-ante, $\mathrm{n}$-period, real interest rate is expressed as follows

$$
r_{e a, t}^{*}=\bar{r}+\left(\rho_{\pi}-1\right)\left(E_{t}\left[\pi_{t+n}\right]-\pi_{t+n}^{*}\right)+\rho_{y} y_{t}+\rho_{q} q_{t}
$$

where $r_{e a, t}^{*}=i_{t}^{*}-E_{t}\left[\pi_{t+n}\right]$ is the ex-ante real interest rate and $\bar{r}$ is the equilibrium real interest rate. In this specification, if $\rho_{\pi}$ is greater than one, the real interest rate increases whenever expected inflation is above the target level. In this case, the central bank tries to stabilize inflation. On the contrary, when $\rho_{\pi}$ is less than one, the central bank moves the interest rate in order to partially accommodate any increase in the expected level of inflation. As a result, the monetary authority is not stabilizing inflation.

Now, in order to obtain an expression for the ex-post real interest rate, we add and subtract the actual inflation over $t+n$ on the left hand side of (9). Then, the ex-post real interest rate is defined as

$$
r_{t}^{*}=\bar{r}+\left(\rho_{\pi}-1\right)\left(E_{t}\left[\pi_{t+n}\right]-\pi_{t+n}^{*}\right)+\rho_{y} y_{t}+\rho_{q} q_{t}+\varepsilon_{t}
$$

where $r_{t}^{*}=i_{t}^{*}-\pi_{t+n}$ is the central's bank target level for the ex-post real interest rate. On the other hand, $\varepsilon_{t}=E_{t}\left[\pi_{t+n}\right]-\pi_{t+n}$ is the inflation prediction error. The specification in equation (10) may be used to see how the CCB sets its policy interest rate; however, this specification does not capture the tendency that a central bank may have to smooth changes in interest rates. Introducing this tendency may be a difficult task, so it is assumed, as in Clarida et al (1998), that the policy interest rate, $r_{t}$, partially adjusts to its target level, $r_{t}^{*}$. This assumption can be expressed as

$$
r_{t}=(1-\rho) r_{t}^{*}+\rho r_{t-1}+v_{t}
$$

where the parameter $\rho \epsilon[0,1]$ captures the degree of interest rate smoothing and $v_{t}$ represents a zero mean real interest rate shock. As is noted by Clarida et al (1998 p.1039), this shock may reflect a 
pure random component to the policy or it could arise because the central bank imperfectly forecasts the demand for reserves. Under this scenario, the interest rate jumps in response to an unexpected movement in the demand for reserves that is orthogonal to movements in inflation, output and the exchange rate.

Now, we combine equations (10) and (11) to obtain an expression for the policy interest rates that allows for inertial behavior and depends only on observable variables

$$
r_{t}=(1-\rho) \bar{r}+(1-\rho)\left[\left(\rho_{\pi}-1\right)\left(\pi_{t+n}-\pi_{t+n}^{*}\right)+\rho_{y} y_{t}+\rho_{q} q_{t}\right]+\rho r_{t-1}+u_{t}
$$

where the policy interest rate, $r_{t}$, is expressed now as a function of realizations of the relevant variables, plus an error term, $u_{t}$. This term is a linear combination of the prediction errors and the policy innovation, $v_{t}$. In particular, $u_{t}$ is defined as

$$
u_{t}=\left\{v_{t}+(1-\rho)\left[\beta\left(E_{t}\left[\pi_{t+n}\right]-\pi_{t+n}\right)+\rho_{y}\left(E_{t}\left[y_{t}\right]-y_{t}\right)+\rho_{q}\left(E_{t}\left[q_{t}\right]-q_{t}\right)\right]\right\}
$$

The specification in (12) is the expression to be estimated empirically. One advantage of this formulation is that all the dependent variables are future and current realizations of observable variables. Therefore, we avoid the problem of modelling, explicitly, the agent's expectations.

\section{Estimation}

We use data on a monthly frequency ${ }^{10}$. Information is available from 1986.01 to 2000.12. The estimation sample is from 1990.09 to 2000.12 which is the inflation targeting period.

The policy reaction function to be estimated is equation (12) that contains all the parameters of interest. In fact, in that specification, it is straightforward to test whether the real exchange rate and the output misalignments are objectives of the central bank - independently of their impact on future inflation. In this case, a simple t-test on the significance of $\rho_{y}$ and $\rho_{q}$ can be performed. If $\rho_{y}$ and $\rho_{q}$ are statistically different from zero, then it is not possible to reject the hypothesis that the central bank has additional objectives besides controlling inflation.

Now, it is evident that the correlation between the error term, $u_{t}$, and future inflation in (12) is different from zero. In these circumstances, estimating this relationship with Ordinary Least Squares

\footnotetext{
${ }^{10}$ Appendix A contains a detailed description of the series we use.
} 
(OLS) will generate biased estimators. To overcome this problem, equation (12) is estimated using the Generalized Method of Moments (GMM), as in Clarida et al (1998 and 2000).

To apply GMM, it is necessary to impose an orthogonality condition between the error term in (12) and a set of instrumental variables that reflect the information available at time $t$. In particular, let $Z_{t}$ be the set of instruments orthogonal to $u_{t}$ so that $E\left[Z_{t} u_{t}\right]=0$. This orthogonality condition can be expressed as

$$
E_{t}\left\{\left(r_{t}-(1-\rho) \bar{r}-(1-\rho)\left[\left(\rho_{\pi}-1\right)\left(\pi_{t+n}-\pi_{t+n}^{*}\right)+\rho_{y} y_{t}+\rho_{q} q_{t}\right]\right) Z_{t}\right\}=0
$$

where the set of instruments is known when the CCB sets the real interest rate, $r_{t}$.

The above orthogonality condition can be used to estimate, using GMM, the coefficients that characterize the monetary policy reaction function, $\rho, \rho_{\pi}, \rho_{y}$ and $\rho_{q}$. In particular, GMM provides consistent estimates of the policy coefficients. On the other hand, as is noted by Clarida et al (1998), by construction, the residual series $u_{t}$ features and $M A(n-1)$ structure and empirical moments cannot be considered as serially independent. In order to sort out this problem, we follow the estimation procedure suggested by Favero (2001); when implementing GMM estimation we correct for heteroscedasticity and autocorrelation of an unknown form with a lag truncation parameter of $n-1$. Furthermore, Barlett weights are chosen to ensure positive definiteness of the estimated variance-covariance matrix (see Favero 2001, p.233).

Finally, in order to assess whether a particular set of instruments, $Z_{t}$, is valid, a $J$ - test of overidentifying restrictions is implemented. This test has a $\chi^{2}$ distribution with $m-k$ degrees of freedom, where $m$ is the number of instruments used and $k$ is the number of variables to be instrumented.

\subsection{Identifying the Cyclical Component in the Series}

Some of the explanatory variables are expressed as deviations from the steady state or equilibrium level. In order to obtain empirical estimates of the output gap, $y_{t}$, and the exchange rate misalignment, $q_{t}$, different filtering techniques can be applied. For instance, Parrado (2000), in a similar exercise for Chile, used a quadratic detrending procedure to obtain the long-run level of output. Then the output gap, $y_{t}$, is constructed as the percentage difference between the output level and its long-term value. Similarly, Scmidt-Hebbel and Tapia (2002) use the Hodrick-Prescott (HP) filter to obtain $y_{t}$ and $q_{t}$. 
In this paper, we use an alternative methodology: in order to determine the output gap, $y_{t}$, and the exchange rate misalignment, $q_{t}$, a structural times series (STSM) model is fitted to the level of output and to the level of the real exchange rate. The STSM gives the cyclical component of each series and we use this component as a measure of the output gap, $y_{t}$, and the exchange rate misalignment, $q_{t}$. Using this approach has the advantage of avoiding the creation of spurious cycles, which can be one of the consequences of using a HP ad-hoc filtering procedure (see Harvey and Jaeger 1993). Another advantage of this procedure is that the irregular movements of the series are separated from the cycle. In this way, the series we obtain do not contain noisy information that is sometimes difficult to interpret.

\subsubsection{Trend plus Cycle Model}

The STSM we use is the trend plus cycle model ${ }^{11}$. Applying this procedure to the Chilean level of output $^{12}$ results in an output gap series, $y_{t}$, that is less volatile than the series obtained with the HP filter (see Figure 3). On the other hand, the output gap obtained by using linear or quadratic detrending procedures is much noisier. The cyclical component obtained from the HP, linear and quadratic detrending procedures is much more volatile, because it includes the irregular movements in output which appear to be substantial ${ }^{13}$. On the contrary, when a structural times series model is fitted, the irregular component is removed from the cycle. As a result, the output gap series in the lower panel of Figure 3 is less volatile.

From an economic perspective, the cycle obtained with the STSM has a meaningful interpretation. In fact, it captures many of the stylized facts of the Chilean business cycle. In particular, the slowdown of the Chilean economy at the beginning of the 90s and the subsequent recovery, between 1992 to 1994, are well reflected by this cycle. On the other hand, the rapid expansion of the economy between 1997 and mid-1998 and the subsequent crisis in 1999 are also captured. Finally, the slow recovery of the economy in 2000 and 2001 is reflected at the end of the period.

To obtain the cyclical component of the real exchange rate, $q_{t}$, the same procedure as before is applied: a trend plus cycle model is fitted to the level of the real exchange rate. As before, the cycle

\footnotetext{
${ }^{11}$ Appendix B explains, in more detail, the trend plus cycle model.

${ }^{12}$ The models have been estimated using STAMP 6.0 software.

${ }^{13}$ Changing the smoothing parameter in the HP does not change the results; for alternative values of this parameter, the HP cycle is always noisier than the cycle obtained using a structural time series model.
} 
Figure 3: Chile: Output Gap
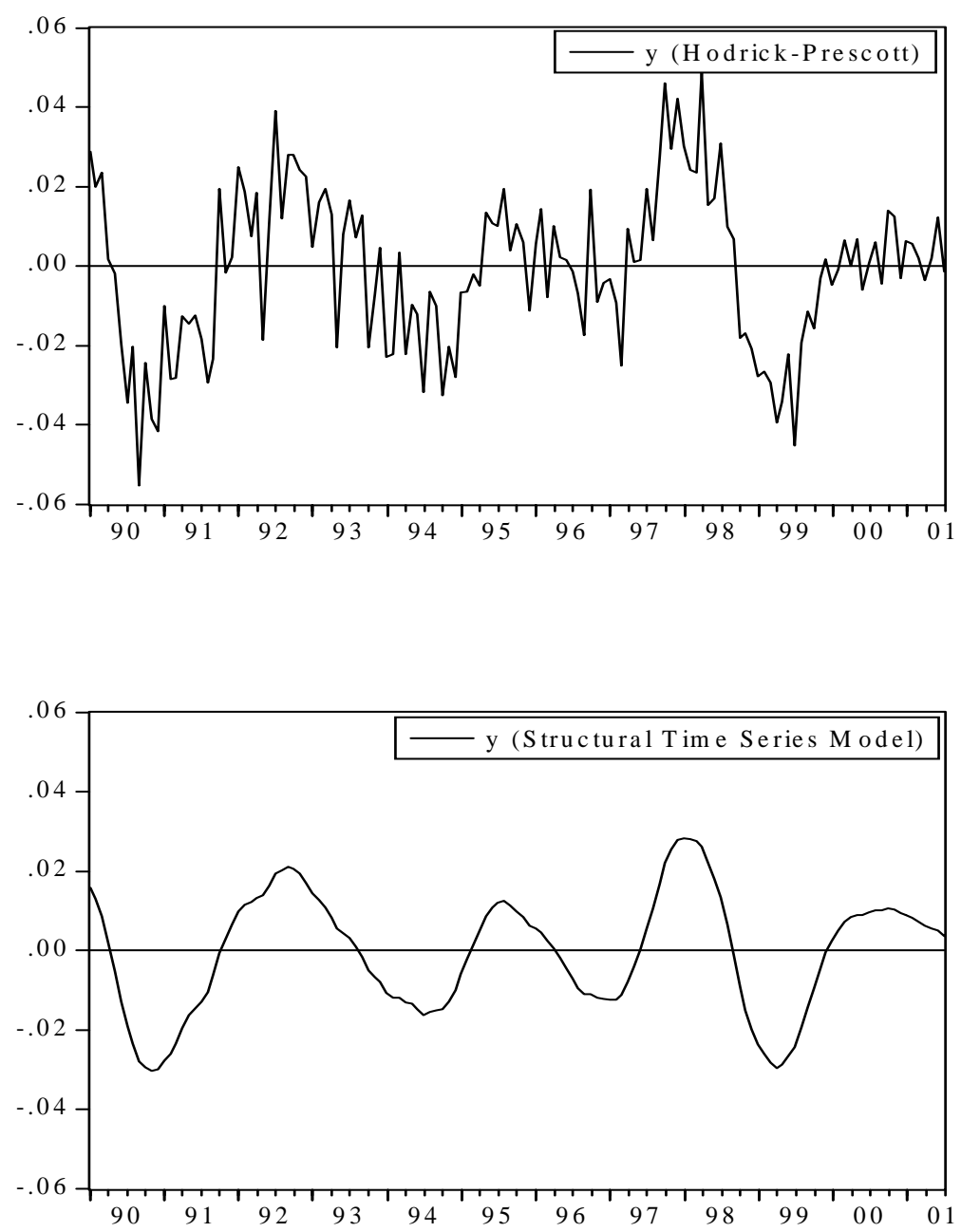

obtained by fitting a STSM is less volatile than the cycle obtained using the HP filter (see Figure 4). On the other hand, the series obtained with the HP filter presents a seasonal pattern with appreciations at the beginning of each year. This may reflect changes in seasonality that are not captured by the HP procedure. In fact, Harvey (2001) argues that changes in seasonality may not be captured by the non-model-based seasonal adjustment procedure, such as the U.S. Census Bureau's X-12 used when filtering by HP. Again, this problem is overcome when using a structural time series model.

The economic interpretation of real exchange rate deviations is more difficult. In fact, there is no consensus in Chile about the level of the equilibrium real exchange rate in the past decade. Many economists have suggested that an important degree of real appreciation was present in the 90s, but 
Figure 4: Chile: Real Exchange Rate Deviations
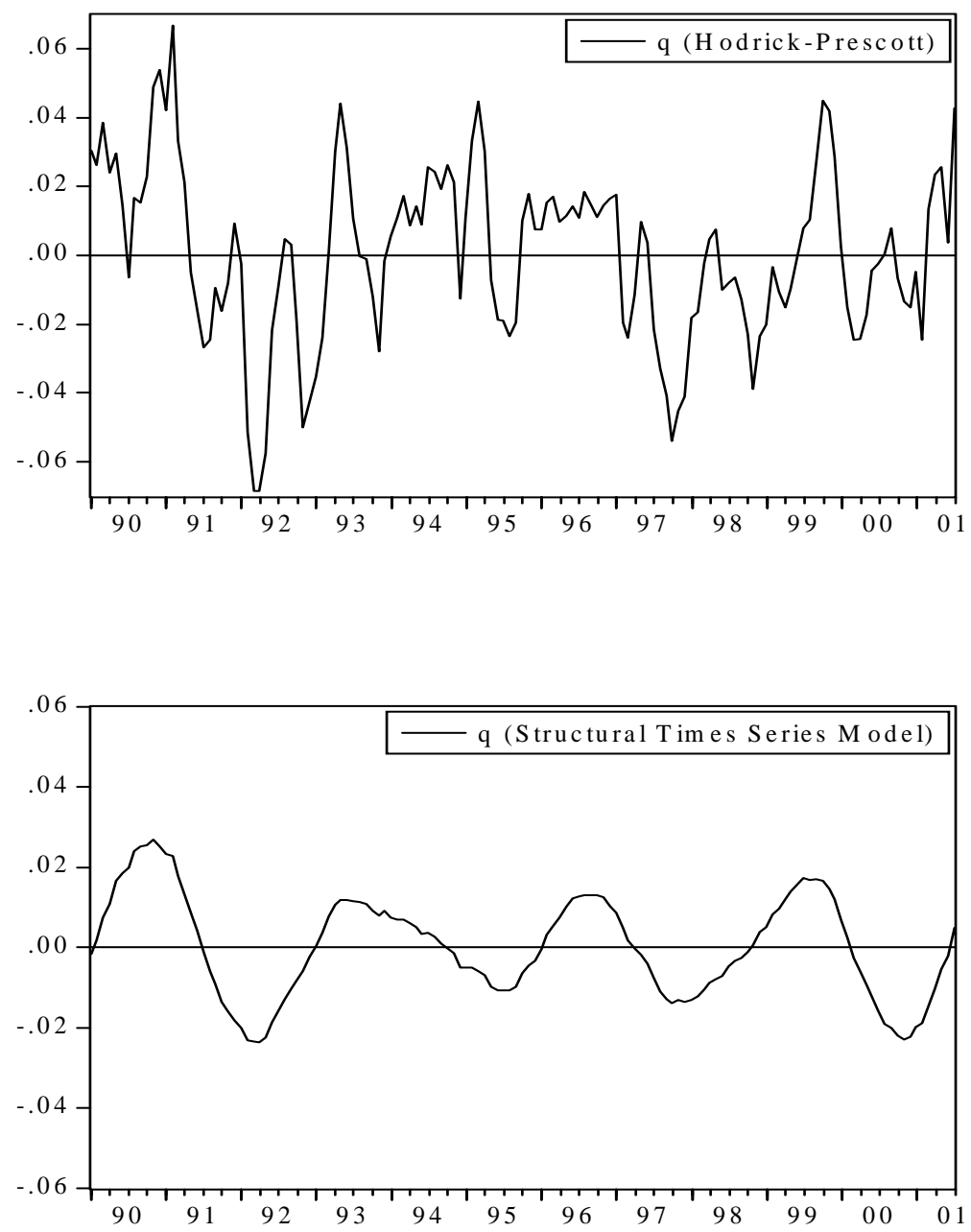

there is no a clear description of this appreciation path on a monthly basis. In any case, the pressure over the exchange rate market in 1998-1999 is well reflected by the real exchange rate misalignments presented in Figure 4.

Finally, for inflation, we do not need to use any detrending procedure, instead we compute the inflation gap, $\pi_{t+n}-\pi_{t+n}^{*}$, as the difference between actual inflation and target inflation ${ }^{14}$. The series is presented in Figure 5

\footnotetext{
${ }^{14}$ See Appendix A for a description of each variable.
} 
Figure 5: Chile: Inflation Deviation from Target

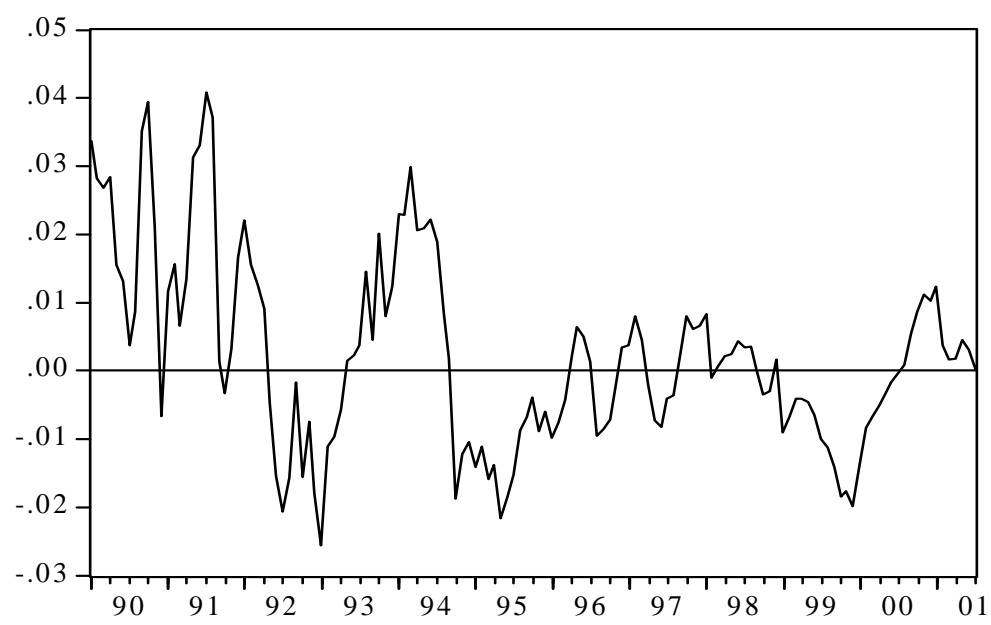

\section{Results}

In this section, we present the results of estimating the policy reaction function in (12) and three alternative specifications. As is noted by Clarida et al (1998), in order to implement GMM the interest rate and the independent variables have to be stationary. We perform a standard Dickey-Fuller test and the null hypothesis that the series are I(1) is rejected.

We assume $n=15$, which is consistent with the way in which the CCB sets its inflation targets ${ }^{15}$. On the other hand, due to the lag in the availability of information, the CCB cannot observe output in $\mathrm{t}$ or in $\mathrm{t}-\mathrm{1}^{16}$. As a result, at time $\mathrm{t}$ the CCB forms expectations about $y_{t-1}$ based on past information. In a similar way, the $\mathrm{CCB}$ cannot observe perfectly the contemporaneous level of real exchange rate misalignments; hence, at time $\mathrm{t}$, it forms expectations about $q_{t}$.

Now, the set of instruments, $Z_{t}$, includes a constant, five lags of the output gap (from t-2), three lags in the policy interest rate, lags one to six and lag number nine and twelve of the inflation gap, three lags in the real exchange rate, and three lags in the terms of trade variation. In all cases, the $J$-test ${ }^{17}$ cannot reject the validity of this set of instruments.

\footnotetext{
${ }^{15}$ Each year, the CCB announces, fifteen months in advance, the inflation target.

${ }^{16}$ At time $t$ it is only possible to observe output in $t-2$.

${ }^{17}$ This test has a $\chi_{m-k}^{2}$ distribution where $m$ is the number of instruments and $k$ is the number of coefficients to be estimated.
} 


\subsection{Linear Policy Response to the Exchange Rate}

In the second column of Table 1, we present the result of estimating by GMM the monetary policy reaction function in (12). The implicit assumption in this formulation is that the policy response to real exchange rate deviations, $\rho_{q}$, is linear. This assumption will be removed later on.

As expected, the results for show a positive and significant response to expected inflation, $\left(\rho_{\pi}-1\right)=$ 0.786. This is consistent with the widespread view that, since 1990, the CCB has responded aggressively to inflation deviations from target. On the other hand, CCB's responses to output, $\rho_{y}$, and to the real exchange rate, $\rho_{q}$, are positive and significant. In particular, it is possible to reject the null hypothesis that $\rho_{y}=0$ and $\rho_{q}=0$. This latter result indicates that the CCB had some concerns about output and real exchange rate deviations, even though they were not explicit monetary policy targets. In comparative terms, the policy response to the real exchange rate, $\rho_{q}$ is larger in Chile than in developed economies. In fact, relative to the policy response to expected inflation $\left(\rho_{q} / \rho_{\pi}\right)$, the reaction to real exchange rate misalignments is ten times bigger in Chile than in Germany and the UK ${ }^{18}$ and eight times bigger than in Japan ${ }^{19}$. In a similar way, the relative response to output misalignments, $\rho_{y} / \rho_{\pi}$, is also bigger in Chile.

On the other hand, the average real interest rate during this period, $\bar{r}$, is $5.2 \%$ and the degree of inertia in the policy is high; $\rho=0.878$. However, the degree of policy inertia is somehow lower that the inertia found in developed economies. In particular, Clarida et al (1998) find values for $\rho$ between $\rho=0.91$ and $\rho=0.95$.

\subsection{Testing the Importance of Lagged Inflation}

In order to test whether the central bank is, indeed, reacting to expected rather than to past inflation, we estimate an alternative specification for the monetary policy reaction function. In particular, we allow for the possibility that the central bank reacts, also, to lagged inflation. By doing so, it is possible to test whether the IFB monetary policy specification in (12) is more appropriate than a backward-looking Taylor-type monetary policy rule. The extended policy rule that includes lagged inflation is

\footnotetext{
${ }^{18}$ See Clarida et al (1998 p.1045) who presents, in Table 1, the monetary policy coefficients for Germany and in Table 4 (p.1055) the policy coefficients for the UK.

${ }^{19}$ See Clarida et al (1998) who presents in Table 2 (p.1047) the policy coefficients for Japan.
} 
Table 1: Chile: Monetary Policy Rule. Baseline Estimates.

\begin{tabular}{|c|c|c|c|c|}
\hline Coefficients & Rule in (12) & $\begin{array}{l}\text { Rule in }(13) \\
\left.\text { (adding } \pi_{t-1}\right)\end{array}$ & $\begin{array}{c}\text { Rule in (14) } \\
\text { (considers } q_{t}^{L} \text { and } q_{t}^{S} \text { ) }\end{array}$ & $\begin{array}{l}\text { Rule in (15) } \\
\text { (longer horizon for } \pi_{t+n} \text { ) }\end{array}$ \\
\hline $\bar{r}$ & $\begin{array}{l}0.052^{* *} \\
(0.002)\end{array}$ & $\begin{array}{l}0.068^{* *} \\
(0.003)\end{array}$ & $\begin{array}{l}0.052^{* *} \\
(0.002)\end{array}$ & $\begin{array}{l}0.050^{* *} \\
(0.003)\end{array}$ \\
\hline$\rho$ & $\begin{array}{l}0.878^{* *} \\
(0.024)\end{array}$ & $\begin{array}{l}0.961^{* *} \\
(0.017)\end{array}$ & $\begin{array}{l}0.893^{* *} \\
(0.021)\end{array}$ & $\begin{array}{l}0.930^{* *} \\
(0.014)\end{array}$ \\
\hline$\left(\rho_{\pi}-1\right)$ & $\begin{array}{l}0.786^{* *} \\
(0.179)\end{array}$ & $\begin{array}{l}2.486 \\
(1.120)\end{array}$ * & $\begin{array}{l}0.703^{* *} \\
(0.187)\end{array}$ & $\begin{array}{l}2.263^{* *} \\
(0.632)\end{array}$ \\
\hline$\rho_{y}$ & $\begin{array}{l}1.122^{* *} \\
(0.314)\end{array}$ & ${ }_{(1.749)}^{4.302}$ * & $\begin{array}{l}1.386^{* *} \\
(0.319)\end{array}$ & $\begin{array}{l}2.919^{* *} \\
(0.645)\end{array}$ \\
\hline$\rho_{q}$ & $\begin{array}{l}0.633^{* *} \\
(0.176)\end{array}$ & $\begin{array}{l}3.519^{* *} \\
\text { (1.295) }\end{array}$ & - & $\begin{array}{l}1.907^{* *} \\
(0.403)\end{array}$ \\
\hline$\left(\rho_{\pi}-1\right)^{b}$ & - & $\begin{array}{l}0.631 \\
(0.455)\end{array}$ & & - \\
\hline$\rho_{q}^{L}$ & - & - & $\begin{array}{l}0.860^{* *} \\
(0.197)\end{array}$ & - \\
\hline$\rho_{q}^{S}$ & - & - & $\begin{array}{l}0.557 \\
(0.545) \\
\end{array}$ & - \\
\hline$J-T e s t$ & $6.8[0.99]$ & $5.3[0.98]$ & $7.0[0.99]$ & $5.3[0.99]$ \\
\hline
\end{tabular}

The J-Test for overidentifying restrictions has a $\chi_{m-k}^{2}$ distribution.

Standard Errors in parentheses () and p-values in brackets []

${ }^{* *}$ Significant at $99 \%$ and ${ }^{*}$ significant at $90 \%$ 


$$
r_{t}=(1-\rho) \bar{r}+(1-\rho)\left[\left(\rho_{\pi}-1\right)\left(\pi_{t+n}-\pi_{t+n}^{*}\right)+\rho_{y} y_{t}+\rho_{q} q_{t}+\left(\rho_{\pi}-1\right)^{b} \pi_{t-1}\right]+\rho r_{t-1}+u_{t}
$$

where the coefficient $\left(\rho_{\pi}-1\right)^{b}$ represents the policy response to lagged inflation, $\pi_{t-1}$.

We estimate equation (13) using the same set of instruments as before. The results are presented in Table 1 third column. The policy response to lagged inflation, is positive but it is not statistically significant. On the other hand, the policy responses to the rest of the variables increases substantially. In fact, $\left(\rho_{\pi}-1\right)$ goes from 0.786 to 2.486 , the response to output misalignments, $\rho_{y}$, increases from 1.122 to 4.302 and the policy reaction to the exchange rate, $\rho_{q}$, increases from 0.633 to 3.519. Finally, the degree of policy inertia, $\rho$, increases from 0.878 to 0.961 .

From the preceding results, it is clear that the long term policy responses, $\rho_{\pi}, \rho_{y}$ and $\rho_{q}$ increase substantially. However, because the inertial coefficient increases, too, the short-term policy responses, $(1-\rho) \rho_{\pi},(1-\rho) \rho_{y}$ and $(1-\rho) \rho_{q}$ do not change as much. In fact, the short-term response to expected inflation, $(1-\rho) \rho_{\pi}$, goes from 0.096 to 0.098 , the short-term response to expected output, $(1-\rho) \rho_{y}$, goes from 0.136 to 0.169 and short-term response to the exchange rate, $(1-\rho) \rho_{q}$, goes from 0.077 to 0.138 . Hence, introducing the lagged value of inflation does not alter, substantially, the short-term policy responses (the exception being the short-term response to the exchange rate).

\subsection{Testing Nonlinear Responses to the Real Exchange R ate}

It has been argued, by Calvo and Reinhart (2002), that monetary policy can be determined by exchange rate considerations. In particular, developing economies may react to exchange rate misalignment because the abandonment of an exchange rate regime may cause important economic disruptions.

In Chile, the CCB had an explicit band for the nominal exchange rate but, as we discuss in Section 2.2 , it was not supposed to use the interest rate to fulfill this objective.

In practice, however, the CCB may respond to real exchange rate fluctuations even if those fluctuations are consistent with the nominal exchange rate band. In fact, fluctuations in the exchange rate may signal a probability of devaluation. In this case, the monetary authorities will try to avoid an exchange rate collapse by defending a non-explicit exchange rate target. This reaction corresponds to the "fear of floating" suggested by Calvo and Reinhart (2002). 
The above argument is also consistent with Vitale's (2003) theoretical results; a monetary authority that wants to signal a new level for the exchange rate may use both foreign exchange rate interventions and the monetary policy instrument. In fact, Vitale (2003), shows that monetary policy decisions and foreign exchange rate interventions may be correlated. If a central bank is in charge of both interest rates decisions and foreign exchange rate interventions - as was the case in Chile until September 1999 it can intervene in the exchange market to signal the implicit target for the exchange rate. In particular, it buys (sells) the foreign currency to signal a greater (smaller) than expected target for the exchange rate. In this case, a reduction (increase) in the interest rate also generates a greater (smaller) than expected target for the exchange rate. Hence, a reduction (increase) in the interest rate is a policy reaction that is consistent with this signal. Therefore, when the central bank perceives a real exchange rate misalignment, it may use both foreign exchange rate interventions and the monetary policy interest rate to correct it.

In some ways, the fact that $\rho_{q}>0$ in the (Table 1 second and third column) indicates that the CCB wanted to stabilize the real exchange rate independently of its inflationary impacts. However, it is difficult to distinguish whether the CCB is reacting just to large real exchange rate misalignments. In fact, large misalignments may signal a higher probability of real exchange rate collapse therefore they have to be avoided. On the other hand, relatively small deviations may be transitory events with no further implications for the exchange rate regime. As a consequence, the central bank may not intervene in this case.

In order to test whether CCB's response to the real exchange rate is linear, we re-state equation (12). In particular, we allow for differentiated responses to different levels of real exchange rate misalignment. In doing so, we split real exchange rate deviations into "small" and "large" ones 20. Then, equation (12) can be expressed as

$$
r_{t}=(1-\rho) \bar{r}+(1-\rho)\left[\left(\rho_{\pi}-1\right)\left(\pi_{t+n}-\pi_{t+n}^{*}\right)+\rho_{y} y_{t}+\rho_{q}^{L} q_{t}^{L}+\rho_{q}^{S} q_{t}^{S}\right]+\rho r_{t-1}+u_{t}
$$

where $\rho_{q}^{L}$ is the policy response to large real exchange rate misalignments, $q_{t}^{L}$, and $\rho_{q}^{S}$ is the policy response to small real exchange rate misalignments, $q_{t}^{S}$.

\footnotetext{
${ }^{20} \mathrm{We}$ assume that large deviations are equal or greater than $1.5 \%$ (in absolute value) and small ones are smaller than $1.5 \%$. Under this assumption, roughly half of the observations in the period 1986.01 to 2001.12 correspond to "large deviations".
} 
The results of estimating equation (14) are presented in Table 1 fourth column ${ }^{21}$. We conclude that, in the face of larger real exchange rate misalignments, the CCB reacts more strongly. In particular, in that case, the policy response to the real exchange rate increases from $\rho_{q}=0.633$ in the baseline case to $\rho_{q}^{L}=0.860$. On the other hand, the response to small deviations is $\rho_{q}^{S}=0.557$ and it is not statistically significant. Therefore, the response to the real exchange rate is nonlinear: the CCB reacts more aggressively to larger exchange rate misalignments

\subsection{Testing the Importance of Longer Expected Inflation Horizons}

The formulation in (12) can be modified to allow for responses not only to a specific target in time, $\left(\pi_{t+n}-\pi_{t+n}^{*}\right)$, but to a path of future inflation gaps. As suggested by Wadhwani (2000), in the shortrun, policymakers may react to exchange rate fluctuations to stabilize the future path of inflation and not only of specific inflation targets. In fact, if exchange rate misalignment affects the future path of inflation (relative to the horizon that is considered in the design of monetary policy), then it is possible that policymakers will react to exchange rate fluctuations, even if those fluctuations do not have any impact on short-run inflation (or, in this case, inflation in $t+15$ ). Hence, a positive value of $\rho_{q}$ in equation (12) may just reflect a concern for inflation beyond $t+15$ and not a concern for the real exchange rate per se.

A way in which we can test the above hypothesis is by re-expressing equation (12) as

$$
r_{t}=(1-\rho) \bar{r}+(1-\rho)\left[\left(\rho_{\pi}-1\right) \sum_{n=15}^{24} \frac{\left(\pi_{t+n}-\pi_{t+n}^{*}\right)}{10}+\rho_{y} y_{t}+\rho_{q} q_{t}\right]+\rho r_{t-1}+u_{t}
$$

Now, if the monetary authority wants to stabilize the future path of inflation gaps (from $n=15$ to 24 for instance), then $\left(\rho_{\pi}-1\right)>0$ and $\rho_{y}$ and $\rho_{q}$ will capture the degree to which CCB is concerned about output and exchange rate deviations that do not affect this path.

The results of estimating the specification in (15) are presented in Table 1 fifth column. In this case, the central bank reacts to the future path of inflation. In fact, $\left(\rho_{\pi}-1\right)=2.263$. On the other hand, the responses to output deviations and real exchange misalignments are still positive and significant. In particular, $\rho_{y}=2.919$ and $\rho_{q}=1.907$.

\footnotetext{
${ }^{21}$ This estimation set of instruments does not change.
} 
The preceding results indicate that, even in the case where longer horizons for the inflation deviations are considered, the CCB is still concerned about output and exchange rate deviations. This result reinforces the idea that the $\mathrm{CCB}$ has additional, non-explicit, objectives besides controlling inflation.

\section{Robustness Exercises}

The results presented so far show that the CCB policy reaction function can be modelled with an IFB policy rule. In particular, the CCB moves interest rates whenever expected inflation deviates from target. In this context, the CCB is also concerned about output and real exchange rate misalignments. Furthermore, the response to exchange rate misalignments is nonlinear: in the face of large real exchange rate misalignments the policy response is more aggressive.

In this section, we test whether the preceding results are robust to alternative definitions of the explanatory variables. In particular, we consider the case in which output deviations and exchange rate misalignments are generated with the non-model based Hodrick-Prescott filter. We also test whether the CCB reacts to exchange rate deviations from the central parity. Finally, we determine how long it takes the exchange rate to affect inflation. If the pass-through is almost immediate, then the coefficient $\rho_{q}$ may reflect a response to very short-term inflation rather than a genuine concern about exchange rate fluctuations.

\subsection{Results with the Hodrick-P rescott Filter}

In the following exercises, the variables $y_{t}$ and $q_{t}$ are computed using the HP filter. The set of instruments is the same as before. However, the $y_{t}$ and the $q_{t}$ series that are included in this set are the series generated with the HP filter.

In the first exercise, the IFB monetary policy rule in (12) is reestimated. The results, presented in the second column of Table 2, are very similar, in quantitative and qualitative terms, to the results in the baseline estimation. In particular. the CCB reacts to expected inflation deviations from target with a concern for output and real exchange rate fluctuations.

In the second exercise, we reestimate the IFB rule in equation (13) that allows for a policy response to lagged inflation. Again, the HP filter is used to compute $y_{t}$ and $q_{t}$. The results, presented in the 
Table 2: Chile: Monetary Policy Rule. Alternative Estimates

\begin{tabular}{|c|c|c|c|c|}
\hline Coefficients & Rule in (12) & Rule in (13) & Rule in (14) & Rule in $(13)^{a}$ \\
\hline $\bar{r}$ & $\begin{array}{l}0.062^{* *} \\
(0.002)\end{array}$ & $\begin{array}{l}0.057^{* *} \\
(0.001)\end{array}$ & $\begin{array}{l}0.063^{* *} \\
(0.001)\end{array}$ & $\begin{array}{l}0.056^{* *} \\
(0.001)\end{array}$ \\
\hline$\rho$ & $\begin{array}{l}0.922^{* *} \\
(0.012)\end{array}$ & $\begin{array}{l}0.847^{* *} \\
(0.019)\end{array}$ & $\begin{array}{l}0.912^{* *} \\
(0.015)\end{array}$ & $\begin{array}{l}0.698^{* *} \\
(0.015)\end{array}$ \\
\hline$\left(\rho_{\pi}-1\right)$ & $\begin{array}{l}0.769^{* *} \\
(0.306)\end{array}$ & $\begin{array}{l}0.420^{* *} \\
(0.114)\end{array}$ & $\begin{array}{l}0.570 \\
(0.280)\end{array}$ & $\begin{array}{l}0.429 \\
(0.304)\end{array}$ \\
\hline$\rho_{y}$ & $\begin{array}{l}1.833^{* *} \\
(0.299)\end{array}$ & $\begin{array}{l}0.523^{* *} \\
(0.104)\end{array}$ & $\begin{array}{l}1.622^{* *} \\
(0.311)\end{array}$ & $\begin{array}{l}1.257^{* *} \\
(0.331)\end{array}$ \\
\hline$\rho_{q}$ & $\begin{array}{l}0.667^{* *} \\
(0.115)\end{array}$ & $\begin{array}{l}0.185^{* *} \\
(0.037)\end{array}$ & - & $\begin{array}{l}-0.148^{* *} \\
(0.049)\end{array}$ \\
\hline$\left(\rho_{\pi}-1\right)^{b}$ & - & $\begin{array}{l}0.477^{* *} \\
(0.093)\end{array}$ & - & $\begin{array}{l}0.687^{* *} \\
(0.190)\end{array}$ \\
\hline$\rho_{q}^{L}$ & - & - & $\begin{array}{l}0.564^{* *} \\
(0.129)\end{array}$ & - \\
\hline$\rho_{q}^{S}$ & - & - & $\begin{array}{l}1.017^{* *} \\
(0.333) \\
\end{array}$ & - \\
\hline$J-T e s t$ & $7.6[0.99]$ & $7.3[0.98]$ & $7.5[0.98]$ & $7.0[0.99]$ \\
\hline
\end{tabular}

The J-Test for overidentifying restrictions has a $\chi_{m-k}^{2}$ distribution

Standard Errors in parentheses () and p-values in brackets []

${ }^{* *}$ Significant at $99 \%$ and ${ }^{*}$ significant at $90 \%$

${ }^{a_{\text {The variable }}} q_{t}$ is defined as the percentage deviation of the observed6.

nominal exchange rate from the central parity of the band.

third column of Table 2, show that the CCB reacts to both expected and lagged inflation. As before, the CCB is concerned about output deviations and real exchange rate misalignments. In fact, the policy responses, $\rho_{y}$ and $\rho_{q}$ are both positive and statistically significant ${ }^{22}$.

The third exercise reestimates the IFB monetary policy rule that allows for a nonlinear response to exchange rate misalignments ${ }^{23}$, equation (14). In this case, the CCB is reacting to deviations of expected inflation from target as well as to deviations of output from trend. The coefficients $\left(\rho_{\pi}-1\right)$ and $\rho_{y}$ are positive and significant and their value is similar to the baseline estimates presented in Table 1. In this case, however, the policy response to the real exchange rate does not change with the size of

\footnotetext{
${ }^{22}$ In both cases, the estimated value is below the baseilne estimates.

${ }^{23}$ In this case we split the $q_{t}$ series generated with the HP filter in to large and small deviations. Each group contains the same number of observations.
} 
the real exchange rate misalignments. In particular, $\rho_{q}^{L}=0.564$ and $\rho_{q}^{S}=1.017$.

On the other hand, the hypothesis that $\rho_{q}^{L}=\rho_{q}^{S}$ cannot be rejected ${ }^{24}$. This result sharply contrasts with the nonlinear response to the real exchange rate found in the baseline case (Table 1 second column). The reason for this result is that the Hodrick-Prescott filter does not separate the irregular component from the cycle. As a result, the $q_{t}$ series obtained with the Hodrick-Prescott filter is much noisier (see top panel in Figure 4). This fact implies that, for a given level of real exchange rate misalignment, the $q_{t}$ series obtained with the Hodrick-Prescott filter contains an element, the irregular, that makes it difficult to distinguish whether the level of misalignment is "large" or "small". In fact, suppose that an observation has an underlying cyclical component of zero but it also contains a large irregular element. In theory, this observation should be classified as a small real exchange rate misalignment (the cyclical deviation is zero). However, the large irregular element will determine that, in practice, the observed real exchange rate misalignment is far from zero and therefore this observation will be classified (wrongly) as a large misalignment. The preceding problem is absent from the $q_{t}$ series obtained with a structural times series model and we believe that this is the reason why we find significant differences between $\rho_{q}^{L}$ and $\rho_{q}^{S}$ in the baseline exercise. Also, this is another reason why it is preferable to use the $q_{t}$ series obtained with a structural times series model.

The last exercise in this subsection consists of testing whether the CCB reacts to an alternative definition of the exchange rate misalignment. In particular, given the exchange rate band present in Chile in the nineties, we test whether nominal exchange rate deviations from the central parity of this band generate a monetary policy response. In the last column of Table 2 we present the results of estimating an IFB policy rule with this alternative definition for the exchange rate. The results show that the CCB reacts to inflation deviations from target (past and expected values) as well as to output deviations from trend. However, the reaction to exchange rate deviations from the central parity has the opposite sign, $\rho_{q}=-0.148$. Hence, we do not find evidence that monetary policy has been used to avoid deviations of the nominal exchange rate from the central parity of the band.

\subsection{Exchange R ate Pass-through to Inflation}

As mentioned previously, the $\rho_{q}$ coefficient may reflect a response to very short-term inflation rather than a genuine concern about exchange rate fluctuations. To see whether this is the case, we estimate

\footnotetext{
${ }^{24}$ The wald test for the $H_{0}: \rho_{q}^{L}=\rho_{q}^{S}$ is 1.305 . Hence the $H_{0}$ cannot be rejected at any conventional confidence level.
} 
Figure 6: Inflation Response to a Real Exchange Rate Shock

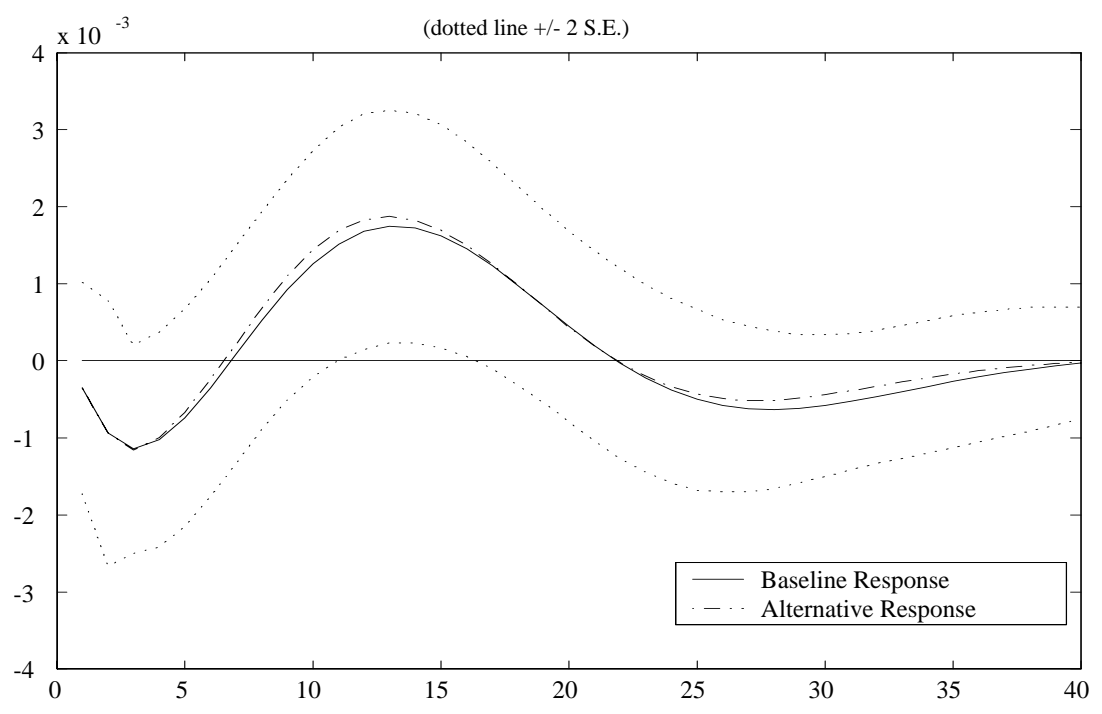

the number of periods that an exchange rate shocks takes to impact on inflation. In doing so, we estimate an unrestricted VAR that contains the following variables: $\left(\pi_{t}-\pi_{t}^{*}\right), y_{t}, r_{t}$ and $q_{t}^{25}$. Then we compute the response of inflation deviation, $\left(\pi_{t}-\pi_{t}^{*}\right)$, to a real exchange rate shock. The results, presented in Figure 6, indicates that the maximum impact of a real exchange rate shock is reached between eleven and sixteen months after the shock (see solid line in Figure6).

An alternative response can be generated if we assume that the central bank does not react to real exchange rate misalignments. This exercise is equivalent to setting to zero the coefficient in the VAR that captures the interest rate response to the real exchange rate. In this alternative scenario, the response of inflation does not change significantly (see Alternative Response line in Figure 6).

The preceding exercises have shown that real exchange rate shocks take between eleven and sixteen months to impact on inflation. This means that the expected inflation variable in the policy rule (12), $\left(\pi_{t+n}-\pi_{t+n}^{*}\right)$, already contains information about the current level of the real exchange rate, $q_{t}$. As a consequence, the policy response to the real exchange rate, $\rho_{q}$, can be be interpreted as a genuine concern about real exchange rate misalignments.

\footnotetext{
${ }^{25}$ The VAR has two lags according to the Akaike Information Criterion (AIC).
} 


\section{Conclusions}

This paper provides empirical evidence on the way in which a small open economy targets inflation. In particular, using as a case study the Chilean inflation targeting experience of the nineties, we estimate the $\mathrm{CCB}$ monetary policy reaction function.

We conclude that the CCB has been forward-looking: it responds mainly to anticipated inflation as opposed to lagged inflation. Furthermore, we find evidence that the CCB has some implicit objectives; avoiding output and exchange rate deviations from equilibrium. Therefore, even when inflation is under control, the CCB shows some concern about real activity and the evolution of the real exchange rate. In this respect, the CCB monetary policy can be characterized as a flexible approach to inflation targeting, as described in Svensson (1997).

On the other hand, the policy response to the exchange rate, and to output as well, is much more important in Chile than in developed economies. In addition, the CCB's reaction to real exchange rate misalignments is nonlinear: it reacts more strongly to large deviations than to small ones. This provides evidence that the CCB either tries to avoid excessive exchange rate depreciations (fear of floating), or tries to avoid appreciations that may reduce the competitiveness of the economy.

The main results are robust to alternative specifications of the monetary policy reaction function, to different definitions of the variables and to longer targeting horizons.

A novel feature of this paper is the use of structural time series models to derive long run deviations in the relevant variables. We believe this is a better alternative to ad-hoc detrending procedures, like the HP filter.

Finally, this is a descriptive study that characterize the CCB reaction function in the last decade. The normative question of whether this policy is optimal cannot be answered in this framework. In this sense, Chapter 4 assesses the properties of this type of reaction functions in an estimated model of the Chilean economy. 


\section{R eferences}

[1] Alexandre, F; Driffill, J; and Fabio Spagnolo "Inflation Targeting, Exchange Rate Volatility, and International Policy Co-ordination" The M anchester School, vol. 70, no 4, Special Issue, pp 546-569.

[2] Agenor and Montiel (1999) Development Macroeconomics. Princeton University Press.

[3] Anderson, G. and Moore, G (1985) "A Linear Algebraic Procedure for Solving Linear Perfect Foresight Models" E conomic Letters, XVII, pp.247-52.

[4] Amato, J. and Laubach, T. (2001). "Implications of Habit Formation for Optimal Monetary Policy". Federal Reserve, Working Paper.

[5] Ball, L. (1999) "Policy Rules for Open Economies" in Taylor, J. Monetary Policy Rules. The University of Chicago Press.

[6] Batini, N and Haldane, A.(1999) "Forward-Looking Rules for Monetary Policy" in Taylor, J. M onetary Policy Rules. The University of Chicago Press.

[7] Batini, N., Harrison, R., and Millard, S. (2003). "Monetary Policy Rules for Open Economies".J ournal of Economics Dynamics and Control. Forthcoming.

[8] Bernanke, B., Laubach, T., Mishkin, F. and Posen, A. (1999) Inflation Targeting. Lessons from the International Experience. Princeton University Press.

[9] Campbell, J.; Lo, A.and MacKinlay, A. (1999) The Econometrics of Financial Markets. Princeton University Press.

[10] Calvo, G. (1983). "Staggered Prices in a Utility Maximizing Framework". J ournal of M onetary Economics, 12, pp.383-98.

[11] Calvo, G., Reinhart, C. (2002). "Fear of Floating". Quarterly J ournal of Economics. vol.177, pp.379-408.

[12] Chari, W., Kehoe, J. and McGrattan, E. (2000) "Can Sticky Prices Explains Exchange Rate Persistence?" Federal Reserve Bank of Minneapolis Working Papers.

[13] Christiano, L.; Martin, E.; and Evans, C. (2001) "Nominal Rigidities and the Dynamic Effects of a Shock to Monetary Policy" NBER W orking Papers 8403. 
[14] Clarida, R. (2001). "The Empirics of Monetary Policy Rules in Open Economies". International J ournal of Finance and Economics. vol. 6, issue 4, pp.315-23.

[15] Clarida, R.; Gali, J.; Gertler, M.(1998) "Monetary Policy Rules in Practice: Some International Evidence". European E conomic Review, June. pp.1033-67.

[16] Clarida, R., Gali, J., Gertler,M. (2001). "Open versus Closed Economies an Integrated Approach"American Economic Review. May. pp 263-67.

[17] Clarida, R., Gali, J., Gertler,M. (2003). "A Simple Model for International Monetary Policy Analysis"J ournal of M onetary E conomics 49, pp 879-904.

[18] Dennis, R. (2000). "Optimal Simple Targeting Rules for Small Open Economies". Federal Reserve Bank of San Francisco W orking Paper. No 2000-20, December.

[19] Dennis, R. (2003). "Exploring the Role of the Real Exchange Rate in Australian Monetary Policy". The Economic Record. Vol. 79. No 244, March pp.20-38.

[20] Dungey, M. ; Fry, R. ; Gonzalez-Hermosillo, B. ; Martin, V. "International Contagion Effects from the Russian Crisis and the LTCM Near-Collapse" I M F W orking Paper. N.02/74.

[21] English, W., Nelson, W. and Sack, B. (2002) "Interpreting the Significance of the Lagged Interest Rate in Estimated Monetary Policy Rules". Federal Reserve Working Paper N.224.

[22] Favero, C. (2001). A pplied Macroeconometrics. Oxford University Press.

[23] Fry, M, Deanne Julius, Lavan Mahadeva, Sandra Roger and Gabriel Sterne (2000). "Key Issues in the Choice of Monetary Policy Framework" in Monetary Policy Frameworks in a Global Context Mahadeva, L and Gabriel Sterne (2000). Routledge

[24] Fuhrer, J. (1997) "The (Un)Importance of Forward-Looking Behavior in Price Specifications" J ournal of Money, Credit and Banking, Vol.29, N.3, pp.339-50.

[25] Fuhrer, J. (2000). "Habit Formation in Consumption and Its Implications for Monetary-Policy Models". American Economic Review, June, Vol. 90. n3.

[26] Fuhrer, J. and G. R. Moore. (1995a) "Monetary Policy Trade-offs and the Correlation between Nominal Interest Rates and Real Output", American Economic Review, 1995, 85 No 1. 
[27] Fuhrer, J. and Moore, G. (1995b) "Inflation Persistence"Quarterly J ournal of E conomics.February pp.128-159.

[28] Fujii, E. and Chinn, M. (2000) "Fin de Siecle Real Interest Parity". NBER Working Paper No. W7880.

[29] Gali and Gertler (1999). "Inflation Dynamics: A Structural Econometrics Analysis". J ournal of Monetary E conomics., vol.44, pp.195-222.

[30] Gali, J.; Gertler, M. and Lopez-Salido J.D. (2001). "European Inflation Dynamics" European E conomic Review, Vol.45, pp.1237-1270.

[31] Gali, J. and Monacelli, T. (2002), "Optimal Monetary Policy and Exchange Rate Volatility in a Small Open Economy". NBER Working Paper.

[32] Gallego, F; Hernandez, L; Schmidt-Hebbel, K. (2002). "Capital Controls in Chile: Where they Effective?" in Banking, Financial Integration, and International Crisis. Schmidt-Hebbel and Hernandez (editors).

[33] Garcia, P; Herrera L.O.; Valdes, R. (2002) "New frontiers for Monetary Policy in Chile". in Inflation Targeting: Design, Performance, Challenges. Loayza, N. and Soto, R. (editors).

[34] Green, W. (1999) E conometric A nalysis Third Edition Prentice-Hall.

[35] Harvey, A. and Jaeger, A.(1993) "Detrending, Stylized Facts and the Business Cycle" J ournal of A pplied E conometrics, 8, pp.231-47.

[36] Harvey, A.(2002) "Trends Cycles and Convergence".in E conomic Growth: Sources, Trends and Cycles. Loayza, N. and R. Soto (editors).

[37] Jonas, J., and F.S. Mishkin (2003). "Inflation Targeting in Transition Economies:Experience and Prospects". In M. Woodford (ed.), Inflation Targeting. NBER Conference Series. University of Chicago Press.

[38] Keating, J. (1992) "Structural Approaches to Vector Autorregresions". Federal Reserve Bank of St. Louise Review, September/October pp.35-57. 
[39] Kozicki, S. and Tinsley, P. (2002) "Dynamic Specifications in Optimizing Trend-Deviation Macro Model". J ournal of E conomic Dynamics \& Control. Vol.26 Issue 9-10, pp.1585-1611.

[40] Koopman, S.J; Harvey, A.; Doornik and N. Shephard (2000). STA M P 6.0 (Structural Time Series Analyser and Predictor). London: Timberlake Consultants, 2000.

[41] Landerretche, O., Morande, F., Schmidt-Hebbel, K. (2000) "Inflation Targets and Stabilization in Chile" in Monetary Policy Frameworks in a Global Context by Lavan Mahadeva (Editor), Gabriel Sterne (Editor). Routledge.

[42] Leitemo, K. (2003) "Optimal Perception of Inflation Persistence at an Inflation-Targeting Central Bank". mimeo. Norwegian School of Management.

[43] Leitemo, K. and Soderstrom, U. "Simple Monetary Policy Rules and Exchange Rate Uncertainty" J ournal of International M oney and Finance. Forthcoming.

[44] McCallum, B. (2001). "Should Monetary Policy Respond Strongly to Output Gaps?"American Economic Review. May. pp.258-62.

[45] McConnell, M. and Perez-Quiros, G. (2000). "Output Fluctuations in the United States: What Has Changed Since the Early 1980's?". A merican Economic Review, Vol. 90, No.5, pp.1464-1476.

[46] Parrado, E. (2000) "Inflation Targeting and Exchange Rate Rules in an Open Economy". New York University. Mimeographed.

[47] Parrado, E. (2001) "External Shock and the Transmission of the Monetary Policy". Economia Chilena. December (In Spanish).

[48] Parrado, E. and Velasco, A. (2002). "Alternative Monetary Rules in the Open Economy: A welfare Based Approach". in Inflation Targeting: Design, Performance, Challenges. Loayza, N. and Soto, R. (editors).

[49] Rotemberg, J. and Woodford, M. (1997) "An Optimization-Based Econometric Framework for the Evaluation of Monetary Policy: Expanded Version". NBER Technical Working Paper Series.

[50] Rudebusch, G. (2002). "Term Structure Evidence on Interest Rate Smoothing and Monetary Policy Inertia". J ournal of M onetary E conomics, 49. pp.1161-1187. 
[51] Sack, B. (2000). "Does the Fed Act Gradually? A VAR Analysis". J ournal of M onetary E conomics. Vol.46 pp.229-256.

[52] Sack, B. and Wieland, V. (2000) "Interest-Rate Smoothing and Optimal Policy: A Review of Recent Empirical Evidence". J ournal of E conomics and Business, N.52 pp.205-228.

[53] Schmidt-Hebbel, K. and Werner, A. (2002). "Inflation Targeting in Brazil, Chile and Mexico: Performance, Credibility, and the Exchange Rate". J ournal of the Latin American and Caribbean Economic A ssociation. Vol. 2 N.2 pp.31-79.

[54] Schmidt-Hebbel, K. and Tapia, M. "Inflation Targeting in Chile". North American J ournal of Economics and Finance. vol 13. pp.125-146.

[55] Svensson, L. (1997) "Inflation Forecast Targeting: Implementing and Monitoring Inflation Targets". European Economic Review. (41) pp.1111-1146.

[56] Svensson, L. (1998). "Open-Economy Inflation Targeting”. W orking Paper IISE .

[57] Svensson, L. (2000). "Open-Economy Inflation Targeting". J ournal of International Economics, February.

[58] Smets, F. and Wouters, R. (2002). "An Estimated Stochastic Dynamic General Equilibrium Model of the Euro Area". ECB Working Paper Series. No. 171.

[59] Taylor, J. (1999) "The Robustness and Efficiency of Monetary Policy Rules as a Guidelines for Interest Rate Setting by the European Central Bank." J ournal of M onetary Economics, June. pp.655-79.

[60] Taylor, J. (2001). "Using Monetary Policy in Emerging Market Economies". Mimeo Stanford University.

[61] Taylor, J. (2001). "The Role of the Exchange Rate in Monetary-Policy Rules"American Economic Review. May. pp 263-67.

[62] Valdes, R. (1997). "The Transmission of Monetary Policy in Chile". Central Bank of Chile. W orking Paper. 
[63] Valdes, R. and Bennett, H. (2001) "Terms of Trade for Chile a Monthly Series" Central Bank of Chile. Working Paper.

[64] Vitale, P. (2003). "Foreign Exchange Rate Intervention: How to Signal Policy Objectives and Stabilize the Economy". J ournal of Monetary E conomics. Vol.50. Issue 4. pp.841-870.

[65] Wadhwani (2000) "The Exchange Rate and the MPC: What can we do?" Bank of England, May 2000.

[66] Woodford, M. (1999). "Optimal Monetary Policy Inertia". NBER W orking Paper 7261.

[67] Woodford, M. (2002) "Inflation Stabilization and Welfare" mimeo Princeton University.

\section{Appendix}

(Chapter head:)Data

We use monthly time series from 1985.01 to 2002.04. The data $\operatorname{are}^{26}$;

$y_{t}: \log \mathrm{IMACEC}^{27}$ (Source: Central Bank of Chile).

$\pi_{t}$ : Year on year CPI variation (Source: Central Bank of Chile).

$\pi_{t}^{*}$ : Inflation target. (Source: Gallego et al (2002)).

$e_{t}: \log$ of the real exchange rate (Source: Central Bank of Chile).

$r_{t}$ : CCB's domestic real interest rate. This is a hybrid definition: from 1987 to 1995 it is the indexed interest rate on the three months CCB instruments (PRBC 90); from 1995 to 2001 it is the CCB's overnight indexed interest rate (Source: Central Bank of Chile).

tot: Terms of trade. This variable is used as one of the instruments. (Source: Valdes and Bennett (2001)).

(Chapter head:)Univariate time series model

A structural time series model is set up in terms of components that have a direct interpretation. Following Harvey and Jaeger (1993), we specify a univariate time series model as

\footnotetext{
${ }^{26}$ Most data are available from the CCB's webpage; www.bcentral.cl . Alternatively, the data are available, on request, from the author.

${ }^{27}$ The IMACEC is a monthly indicator of economic activity, which covers over $90 \%$ of Chilean GDP.
} 


$$
y_{t}=\mu_{t}+\psi_{t}+\epsilon_{t}, \quad \epsilon_{t} \sim N I D\left(0, \sigma_{\epsilon}^{2}\right)
$$

where $y_{t}$ is the observed series, $\mu_{t}$ is the trend, $\psi_{t}$ is the cycle, and $\epsilon_{t}$ is the irregular component.

The stochastic trend component is specified as

$$
\begin{gathered}
\mu_{t}=\mu_{t-1}+\theta_{t}+\eta_{t}, \quad \eta_{t} \sim \operatorname{NID}\left(0, \sigma_{\eta}^{2}\right) \\
\theta_{t}=\theta_{t-1}+\zeta_{t}, \quad \zeta_{t} \sim \operatorname{NID}\left(0, \sigma_{\zeta}^{2}\right)
\end{gathered}
$$

where $\theta_{t}$ is the slope or gradient of the trend $\mu_{t}$. The irregular $\epsilon_{t}$, the level disturbance $\eta_{t}$ and the slope disturbance $\zeta_{t}$ are mutually uncorrelated.

The statistical specification for the cycle, $\psi_{t}$, is given by

$$
\left[\begin{array}{l}
\psi_{t} \\
\psi_{t}^{*}
\end{array}\right]=\rho\left[\begin{array}{cc}
\cos \lambda_{c} & \sin \lambda_{c} \\
-\sin \lambda_{c} & \cos \lambda_{c}
\end{array}\right]\left[\begin{array}{c}
\psi_{t-1} \\
\psi_{t-1}^{*}
\end{array}\right]+\left[\begin{array}{c}
\kappa_{t} \\
\kappa_{t}^{*}
\end{array}\right]
$$

where $\rho$ is a damping factor such that $0 \leq \rho_{\psi} \leq 1, \lambda_{c}$ is the frequency of the cycle in radians and $\kappa_{t}$ and $\kappa_{t}^{*}$ are two mutually independent white noise disturbances with zero means and common variance $\sigma_{\kappa}^{2}$

Estimation of the hyperparameters, $\left(\sigma_{\epsilon}^{2}, \sigma_{\eta}^{2}, \sigma_{\zeta}^{2}, \rho, \sigma_{\kappa}^{2}\right)$, can be carried out by maximum likelihood. Once this has been done, estimates of the trend, cyclical and irregular components, are obtained from a smoothing algorithm ${ }^{28}$.

\section{Smooth trend plus cycle model}

The model in (16) to (19) can be restricted in order to get a smoother trend. As noted by Harvey (2002), allowing $\sigma_{\zeta}^{2}$ to be positive, but setting $\sigma_{\eta}^{2}$ to zero gives an integrated random walk trend, which when estimated tends to be relatively smooth, this is often referred to as the "smooth trend" model. The above restrictions can be imposed a priori, depending on the nature of the series.

In this context, the HP filter can be understood as a particular case of the smooth trend model. In fact, this filter may be rationalized as the estimator of the trend component in a structural time-series model of the form

\footnotetext{
${ }^{28}$ See Harvey and Jaeger (1993) and Harvey (2002) for empirical applications using the STAMP software.
} 


$$
y_{t}=\mu_{t}+\epsilon_{t}, \quad \epsilon_{t} \sim N I D\left(0, \sigma_{\epsilon}^{2}\right)
$$

where $\mu_{t}$ is defined by equation (17) to (18) and $\sigma_{\eta}^{2}$ and $\psi_{t}$ are set to zero. The optimal filter of (20) which gives the detrended observations, $y_{t}^{d}$, is shown to be

$$
y_{t}^{d}=\left[\frac{(1-L)^{2}\left(1-L^{-1}\right)^{2}}{q_{\zeta}+(1-L)^{2}\left(1-L^{-1}\right)^{2}}\right] y_{t}
$$

where $q_{\zeta}=\frac{\sigma_{\zeta}^{2}}{\sigma_{\epsilon}^{2}}$ is the signal-noise ratio and $L$ is the lag operator. As noted by Harvey and Jaeger (1993), if (20) is believed to be the true model, $q_{\zeta}$ could be estimated by maximum likelihood. Now, the HP filtering procedure, assumes that the true model is (20), that is, it is assumed that $\sigma_{\eta}^{2}=0$ and $\psi_{t}=0$. Furthermore, a value for $q_{\zeta}$ is imposed, rather than estimated. This value, denoted by $\bar{q}_{\zeta}$, is 1/14400 for monthly data. Then, the HP detrended series on a monthly basis, $y_{t}^{H P}$, can be represented as

$$
y_{t}^{H P}=\left[\frac{(1-L)^{2}\left(1-L^{-1}\right)^{2}}{1 / 14400+(1-L)^{2}\left(1-L^{-1}\right)^{2}}\right] y_{t}
$$

Therefore, the HP filter is a restricted smooth trend model in which the cycle component is assumed to be zero and the signal-noise ratio, $\bar{q}_{\zeta}$, is set to a constant number. 